\title{
TWO YEARS' ANALYSIS OF ENVIRONMENTAL RECOVERY TRAINING FOR BIOLOGICAL INCIDENTS
}

\author{
A. Peña-Fernández ${ }^{1}$, M.A. Peña ${ }^{2}$, M.C. Lobo-Bedmar ${ }^{3}$ \\ ${ }^{1}$ De Montfort University, School of Allied Health Sciences, Faculty of Health and Life \\ Sciences (UNITED KINGDOM) \\ ${ }^{2}$ Universidad de Alcalá, Departamento de Ciencias Biomédicas (SPAIN) \\ ${ }^{3}$ IMIDRA, Departamento de Investigación Agroambiental (SPAIN)
}

\begin{abstract}
Environmental recovery in the aftermath of a biological incident is one of the key areas to consider when tailoring a response to protect human health and minimise the spread of the biological agent(s) involved. However, recent studies have highlighted general national and international emergency weaknesses including a lack of preparedness in health care professionals and emergency responders to tackle these events. We undertook a web-based, non-systematic search for biological response training in human health undergraduate programmes in the UK, by using the Google ${ }^{\mathrm{TM}}$ search engine. To the best of our knowledge, there are no undergraduate courses in the UK that directly address this topic. Only a few postgraduate programmes present some information about responding to biological incidents but they do not cover the different phases of a biological incident response, which are: preparedness and situation assessment; exposure assessment; acute health effects; long term health effects; and recovery phase. In order to develop appropriate training, academics from De Montfort University (DMU, Leicester, UK) and the University of Alcalá (Spain) in collaboration with first responders (biomedical scientists) to the 2014-16 Ebola outbreak in Sierra Leone, have developed specific training for undergraduate human health degree students to respond to biological incidents. We have created basic competences to develop this training and distributed them into six domains following the recommendations of the European Commission for medical responders to CBRN emergencies [1]: identification of the risk and risk analysis; toxicological effect of biological agents; planning and organisation of an intervention programme; environmental planning; communication and information management; safety and personal protective equipment; societal and ethical reflections. Following the basic competences created, we developed different training sessions with two components, theoretical (lectures and seminars) and practical (research-led workshop), to cover each of the different phases of an appropriate response to any biological incident. The specific training that covers the recovery phase has been delivered to postgraduate students from the MSc programme in Advanced Biomedical Science at DMU since 2016/17 due to the more manageable student number, time available to deliver the training and greater background knowledge of the class. The analysis of the feedback provided by the first cohort of students indicated high levels of engagement and interest in this training session. We performed some minor modifications following the students' feedback and delivered it this academic course 2017/18 $(n=9)$ to gain more information about its effectiveness in facilitating the specific basic competences covered in this training including the resources used to tailor a recovery response to the case scenario proposed (an outbreak due to Cyclospora spp.) such as the UK Recovery Handbook for Biological Incidents (UKRHBI; PHE, 2015 [2]). All students were satisfied with this training and all highlighted that the tools used aided their learning about environmental recovery $(33.3 \%$ agreed; $66.7 \%$ strongly agreed). All participants indicated that the UKRHBI was an appropriate resource for tailoring a recovery response. Finally, students indicated that they would have liked to have more time to develop a response to the case scenario proposed (the workshop was 2 hours long).
\end{abstract}

Keywords: Biological incidents training, postgraduate students, environmental toxicology.

\section{INTRODUCTION}

Biological incidents and outbreaks of infection are natural, accidental or deliberate (bioterrorism) events that involve the release and spread of biological agents or hazards [3]. Large events involving biological threats can have severe consequences on human health and require rapid and appropriate management to protect the public. However, despite an increase in the occurrence of these incidents in recent years, we have detected a general lack of appropriate training in undergraduate programmes 
within the United Kingdom (UK) for future health care professionals that will act as first responders in the aftermath of any biological incident [4].

As a consequence, we created novel training for human health science students to acquire basic competences that we appropriately developed for these students taking into consideration major skills recently recommended by the European Commission for medical responders to chemical, biological, radiological and nuclear (CBRN) emergencies [1]. The basic competences developed, which are comprehensively described in Peña-Fernández et al. (2016) [5], are aimed to cover the different phases of an appropriate response to a biological incident, which are: preparedness and situation assessment; exposure assessment; acute health effects; long term health effects; and recovery phase.

\subsection{Training to develop a recovery plan in the aftermath of a biological incident}

Our novel training to respond to biological incidents consists of different training sessions with two components [4,6], theoretical (lectures and seminars) and practical (research-led workshop), which covers each of the different phases of a response to a biological incident $[2,7,8]$, including the environmental recovery phase, which is critical to protect human health in the aftermath of an event involving biological hazards $[2,8]$.

This article analyses the effectiveness of the environmental recovery phase part of our novel training for responding to biological incidents.

\section{METHODOLOGY}

To test the effectiveness of the biological recovery training created, we have tested it with MSc. students enrolled in the programme Advanced Biomedical Science at DMU due to its manageable student number (both cohorts had 9 MSc students enrolled), time available to deliver the training and greater background knowledge of the class. We delivered the training in the last two academic courses, because we performed some minor modifications following general feedback provided by the first cohort of MSc students (2016/17).

The training had a highly specialised workshop in which students were asked to tailor a recovery response to the case scenario proposed (an outbreak due to Cyclospora spp.) and the novel methodology developed by Public Health England (PHE) to recover environments affected by biological hazards that can be found in the UK Recovery Handbook for Biological Incidents (UKRHBI; [2]). The UKRHBI provides a series of recovery options or techniques to decontaminate and recover the environment specifically for three types of potential environments impacted by biological hazards: food production systems, water environments and inhabited areas. The user, following the PHE novel methodology, can select the recovery option(s) more applicable and effective for the scenario impacted and according to the physiological characteristic of the biological hazard/pathogen involved $[2,8]$. Students, working in teams, were able to select effective options for their scenario using the UKRHBI and a workbook with all the necessary information about Cyclospora spp.

To analyse this training, we have distributed a Likert scale (strongly disagree, disagree, neither agree nor disagree, agree, strongly agree) questionnaire with open-questions (free-response). Ethical approval was provided by the Research Ethics Committee at DMU (Ref. 1729).

\section{RESULTS AND DISCUSSION}

The results obtained in the feedback-questionnaires used to analyse the novel training implemented in the MSc are described in Table 1 for both academic years. In general, a slight improvement can be observed in the effectiveness of the training in the current cohort of students if the percentages as an indicator. 
Table 1. Responses to the feedback questionnaire, in each academic year, to evaluate novel biological recovery training implemented at DMU in postgraduate teaching ["Advanced Topics in Biomedical

Science"]. Survey results are shown as a percentage of all responses.

\begin{tabular}{|c|c|c|c|c|c|c|}
\hline & Programme & $\begin{array}{l}\text { Strongly } \\
\text { disagree }\end{array}$ & Disagree & $\begin{array}{l}\text { Neither agree } \\
\text { nor disagree }\end{array}$ & Agree & $\begin{array}{c}\text { Strongly } \\
\text { agree }\end{array}$ \\
\hline \multirow{2}{*}{$\begin{array}{l}\text { Content was relevant to the } \\
\text { module }\end{array}$} & $2016 / 17$ & & & & 80 & 20 \\
\hline & $2017 / 18$ & & & & & 100 \\
\hline \multirow{2}{*}{$\begin{array}{l}\text { Duration of the workshop was } \\
\text { appropriate }\end{array}$} & 2016/17 & & & & 100 & \\
\hline & $2017 / 18$ & & & & 100 & \\
\hline \multirow{2}{*}{ Enjoyed the exercise } & $2016 / 17$ & & & 40 & 60 & \\
\hline & $2017 / 18$ & & & & 100 & \\
\hline \multirow{2}{*}{$\begin{array}{c}\text { Workshop was easy to } \\
\text { understand }\end{array}$} & $2016 / 17$ & & & 20 & 60 & 20 \\
\hline & $2017 / 18$ & & & 33.3 & 66.7 & \\
\hline \multirow{2}{*}{$\begin{array}{l}\text { PHE tool aid my learning about } \\
\text { environmental recovery }\end{array}$} & $2016 / 17$ & & & & 60 & 40 \\
\hline & $2017 / 18$ & & & & 33.3 & 66.7 \\
\hline \multirow{2}{*}{$\begin{array}{l}\text { Gained an appropriate } \\
\text { knowledge of public health } \\
\text { prevention and preparedness } \\
\text { against a biological incident }\end{array}$} & $2016 / 17$ & & & & 80 & 20 \\
\hline & $2017 / 18$ & & & & 66.7 & 33.3 \\
\hline \multirow{2}{*}{$\begin{array}{l}\text { Learnt how to establish basic } \\
\text { interventions to protect human } \\
\text { health in the aftermath of a } \\
\text { biological incident }\end{array}$} & 2016/17 & & & & 80 & 20 \\
\hline & $2017 / 18$ & & & & 33.3 & 66.7 \\
\hline \multirow{2}{*}{$\begin{array}{l}\text { Learnt how to tailor a recovery } \\
\text { programme }\end{array}$} & $2016 / 17$ & & & 20 & 80 & \\
\hline & $2017 / 18$ & & & & 100 & \\
\hline \multirow{2}{*}{$\begin{array}{l}\text { Satisfied with the workshop } \\
\text { provided }\end{array}$} & $2016 / 17$ & & & & 100 & \\
\hline & $2017 / 18$ & & & & 66.7 & 33.3 \\
\hline
\end{tabular}

To facilitate the discussion of the results we have taken into account the results only for the current cohort (2017/18) as similar results were gained in both years. Students indicated that they learnt how to establish basic interventions (33.3\% agreed; $66.7 \%$ strongly agreed) to protect human health in the aftermath of a biological incident; and how to select recovery options or implement a recovery plan $(100 \%$ agreed).

Students indicated that the workshop was relatively easy to understand (66.7\% agreed) and reported an acquisition of a certain level of public health prevention knowledge and preparedness against a biological incident $(66.7 \%$ agreed; $33.3 \%$ strongly agreed).

Finally, students were satisfied with the training and workshop provided and reported that the novel UKRHBI (Pottage et al., 2015) aided their learning on environmental recovery (33.3\% agreed; $66.7 \%$ strongly agreed). The usefulness of the UKRHBI as a potential teaching tool for teaching environmental recovery has been also highlighted by $3^{\text {rd }}$ year pharmacy students that used this resource in April 2017 during the delivery of a similar training session at the University of San Pablo CEU in Spain during an Erasmus+ mobility grant [6]. However, an EU or global standardised approach for dealing with the recovery phase would be useful.

\section{CONCLUSIONS}

The analysis of the results collected in the last two academic courses, although preliminary, have demonstrated that the novel training created was effective in facilitating the acquisition of some of the basic competences/skills created for human health students to remediate environments impacted by biological hazards in order to protect human health and minimise infections. Our strategy could be used in other Higher Education Institutions to provide training to face biological incidents to future health care professionals 


\section{ACKNOWLEDGEMENTS}

Disclaimer: the views in this article are those of the authors, not Public Health England.

\section{REFERENCES}

[1] Djalali A., Della Corte F., Segond F., Metzger MH., Gabilly L., Grieger F., Larrucea X., Violi C., Lopez C., Arnod-Prin P., Ingrassia PL. TIER competency-based training course for the first receivers of CBRN casualties: a European perspective. Europen Journal of Emergency Medicine 2017; 24(5):371-376.

[2] Pottage T., Goode E, Shieber C., Wyke S., Speight S., Bennett AM. UK Recovery Handbook for Biological Incidents 2015. PHE publications gateway number 2015406. Available at: https://www.gov.uk/government/publications/uk-recovery-handbook-for-biological-incidents [accessed 07/05/2018].

[3] Brown, N., Crawford, I., Carley, S., Mackway-Jones, K. (2006). A Delphi-based consensus study into planning for biological incidents. Journal of Public Health (Oxf), 28(3), 238-41.

[4] Peña-Fernández A., Escalera Izquierdo B., Peña MA. Evaluating basic training for prevention and response to biological incidents. In: Research in university teaching. Designing the future based on educational innovation. Roig-Vila, Rosabel (ed.). Barcelona: Octaedro, 2017; pp. 358366. ISBN 978-84-9921-935-6.

[5] Peña-Fernández, A., Dunford, L.J., Haris, P.I., Lobo-Bedmar, M.C., Peña, M.A. (2016). Harmonising the training of students within the EU to implement intervention programmes to protect the public in the aftermath of a HazMat incident. ICERI2016 Proceedings, 3559-3565.

[6] Peña-Fernández A., Peña MA., Ollero MD., Hurtado C., Fenoy S. Environmental recovery training for biological incidents: impressions from pharmacy students. EduLearn Proceedings 2017; 5080-5085. ISBN: 978-84-697-3777-4.

[7] Sandström BE, Eriksson H, Norlander L, Thorstensson M, Cassel G. Training of public health personnel in handling CBRN emergencies: a table-top exercise card concept. Environ Int. 2014; 72:164-9.

[8] Pottage T., Goode E., Wyke S., Bennett AM. Responding to biological incidents - what are the current issues in remediation of the contaminated environment? Environ Int 2014; 72:133-9. 